\title{
LA LEY, LA MORAL Y EL DECORO EN EL TEATRO FEMINISTA DEL PRIMER TERCIO DEL SIGLO XX
}

\author{
LAW, MORALITY AND DECORUM IN SPANISH FEMINIST \\ THEATER IN THE EARLY TWENTIETH CENTURY
}

\author{
Fidel López Criado \\ Universidad de La Coruña. La Coruña, España \\ fidel.lopez.criado@udc.es
}

Recibido: 13.10.2013. Aceptado: 24.03.2014.

Resumen: Este trabajo estudia la poco conocida aportación del dramaturgo Manuel Linares Rivas, dentro del "teatro de la cuestión social" de principios del siglo XX, como adalid del primer feminismo español. Para ello, recuperamos tres de sus obras más comprometidas: Aire de fuera (1903), La espuma del champagne (1929) y Fausto y Margarita (1999 [1936]) -piezas de gran éxito de público en su día, pero hábilmente secuestradas y silenciadas por la dictadura franquista, por cuanto suponían de atentado contra la ley, la moral y el decoro del 'nacionalcatolicismo'. A este respecto, nuestro análisis dedica particular atención a la crítica histórico-social del papel de la mujer -hija-esposa-madre, modelada en las virtudes de la Virgen María-, en la pujante sociedad burguesa de finales del siglo XIX, oponiéndola a un nuevo modelo de mujer progresista y librepensadora, que debería liderar la sociedad española en aquel naciente y prometedor siglo XX europeísta.

Palabras clave: Teatro español, teatro feminista, papel de la mujer en el teatro.

\begin{abstract}
This article studies the little known contribution made by the playwright Manuel Linares Rivas to the Spanish feminist movement, within the so called "theater of social concern" at the beginning of the XX Century. To these ends, we recover three of his most controversial plays: Aire de fuera (1903), La espuma del champagne (1929) y Fausto y Margarita (1999 [1936]) -widely acclaimed in their day, but successfully sequestered and silenced soon afterwards by the Francoist dictatorship, inasmuch as they posed a threat to the laws, the morality and the decorum of 'National-Catholicism'. In this regard, our analysis dedicates especial attention to the socio-historical criticism of the role of women -daughter, wife and mother, modelled
\end{abstract}


on the virtues of the Virgin Mary- within the thriving bourgeois society of late XIX Century, opposing her to a new model of a liberal and freethinking woman, who was expected to lead Spanish society in that new and promising European XX Century.

Key words: Spanish theater, feminist theater, role of women in theater.

$\mathrm{E}$ N 1776, LA Declaración de Independencia de los Estados Unidos afirmaba por primera vez en la historia moderna que, a la par del derecho a la vida y a la libertad, todo hombre -léase blanco y exclúyanse mujerestenía el derecho inalienable a ser feliz: the right to life, liberty and the pursuit of happiness ${ }^{1}$. Thomas Jefferson (1743-1823), que había redactado el documento casi en su totalidad, recogía así el pensamiento del materialismo cientificista de David Hume (1711-1776), Immanuel Kant (1724-1804) y Claude Saint-Simon (1760-1825), que conduciría al positivismo de $\mathrm{Au}-$ guste Comte (1798-1857) y, en última instancia, a ese concepto de "estado del bienestar" que caracteriza a las sociedades más avanzadas de la última mitad del siglo $\mathrm{XX}^{2}$. Sin embargo, en el ámbito inmutable de las verdades eternas, la propuesta jeffersoniana era entonces, igual que hoy, un concepto sociopolítico tan novel y revolucionario como ajeno y contrario a esa tradición cristiana que informa la cultura occidental.

\footnotetext{
${ }^{1}$ El texto, en ingles, dice así: "We hold these truths to be self-evident, that all men are created equal, that they are endowed by their Creator with certain unalienable Rights, that among these are Life, Liberty and the pursuit of Happiness". Asimismo, once años después, en la Constitución de los Estados Unidos (1787), se ratifica el principio fundacional del Gobierno como promotor del Estado de bienestar social: "We the People of the United States, in Order to form a more perfect Union, establish Justice, insure domestic Tranquility, provide for the common defence, promote the general Welfare, and secure the Blessings of Liberty to ourselves and our Posterity, do ordain and establish this Constitution for the United States of America" (www. usconstitution.net/const.html). Este concepto llegaría a España décadas más tarde y se incorporaría en el Artículo 13 de la Constitución Española de 1812, donde dice que "el objetivo del Gobierno es la felicidad de la Nación, puesto que el fin de toda sociedad no es otro que el bienestar de los individuos que la componen" (Constitución de la monarquía española. Madrid: Imprenta Nacional, 1845). Puede consultarse el facsímil de la misma en www.congreso.es/docu/constituciones/1812/ce1812_cd.pdf

${ }^{2}$ Nos referimos a ese concepto de estructuración social de las democracias occidentales más avanzadas que, como explican Josep Picó López (1987) y Claudio Olmos y Rodrigo Silva (2011), han asumido ciertas necesidades del ciudadano (sanidad, educación, desempleo, pensiones, dependencia, etc.) como una responsabilidad
} 
La única felicidad (entiéndase: espiritual, que no material) a la que debe aspirar el buen cristiano se encuentra post mortem, como recompensa o culminación de grandes privaciones y sufrimientos en este mundo ${ }^{3}$. En "este valle de lágrimas" del que nos habla "La Salve”, el paraíso había que ganarlo gimiendo y llorando ${ }^{4}$. Y en esa tesitura, la mujer siempre ha llevado la peor parte, lo que seguramente le habrá servido a muchas para ganarse el cielo a pulso (Caine y Sluga, 2000; Marcos, 2004). Sin embargo, la igualdad social, económica y política con el hombre resultaría algo más difícil de conseguir.

Por ello, no es de extrañar que los modelos femeninos -es decir, el modelo de mujer que nos ofrece la tradición judeocristiana- surjan al calor de una preceptiva moral que en el ámbito sociopolítico (Payne, 1984; Witherup, 2003) le es desfavorable $a b$ initio. En Occidente, de la misma manera que el hombre cristiano debe imitar a Cristo, la mujer debe imitar a la Virgen María (Gómez-Acebo, 1999; Navarro, 1987). Ella es, en su función maternal, la máxima expresión de la virtud cristiana en la mujer -como

fundamental del Estado. A este respecto, cabe notar cómo algunos representantes de sensibilidades sociopolíticas conservadoras, cuando no abiertamente reaccionarias, hablan ya del final del "estado de bienestar", que debe ser substituido por una nueva "sociedad participativa", con una mayor iniciativa privada en el ámbito de lo público, en la que el ciudadano, que no el Estado, debe asumir responsabilidad por su propio "bienestar". De esta actitud son buenos ejemplos las declaraciones del flamante rey de Holanda, Guillermo Alejandro (recogidas en "Holanda aboga por substituir el Estado de Bienestar por una 'sociedad participativa”, en El País, el 17 de septiembre de 2013) o la oposición del Partido Republicano de los Estados Unidos al plan de sanidad pública, más conocido como "Obamacare", que amenaza con paralizar la función pública de ese país ("Deadlocked Congress takes U.S. government to brink of shutdown", en Reuters, Washington edition, 30 de septiembre de 2013).

${ }^{3}$ La bibliografía sobre la "doctrina del sufrimiento" como camino de la salvación cristiana es ciertamente extensa, pero sirva como ejemplo el pensamiento de Juan Pablo II en su carta apostólica del 11 de febrero del año 1984 (Salvifici doloris. Carta apostólica sobre el sentido cristiano del sufrimiento humano), donde explica que "de una forma o de otra, el sufrimiento parece ser, y lo es, casi inseparable de la existencia terrena" (1.3) y que "La Sagrada Escritura es un gran libro sobre el sufrimiento" (2.6). Citamos de la edición del Vaticano: LEV, 1999.

${ }^{4}$ Ese espíritu de mortificación y sufrimiento, que caracteriza la vida del cristiano como una experiencia necesariamente dolorosa, está de igual manera presente en todos los devocionarios, dirigidos principalmente a las mujeres cristianas, y cristaliza de manera muy evidente en la Salve, oración que se eleva a la Virgen María como símbolo máximo de piedad y consuelo: "A Ti clamamos los desterrados hijos de Eva; a Ti suspiramos, gimiendo y llorando, en este valle de lágrimas” (Astete, 1977: 9). 
también lo es en el Judaísmo y en el Islam (Bramón, 2009 y 2010; Moreno, 2007 y 2010; Witherup, 2003). Pero recordemos que, en el Antiguo Testamento, libro sagrado común a estas tres grandes religiones monoteístas, dicha maternidad se da como una experiencia dolorosa y de sometimiento al varón -"Tantas haré tus fatigas cuantos sean tus embarazos: con dolor parirás los hijos. Hacia tu marido irá tu apetencia, y él te dominará” ${ }^{-}$, y en esa penitencia de sufrimiento y dominación machista estriba su condición social como ciudadana de segunda clase, sometida al varón, padre o esposo (Muraro, 1991; Osborne, 1993; MacInnes, 2008).

Naturalmente, no es fácil para el hombre cambiar en la tierra lo que Dios ha dispuesto en los cielos, especialmente cuando el mandato divino favorece claramente los intereses del patriarcado en el poder. De ahí que a principios del siglo XX en España -uno de los países más atrasados de Europa, lastrado por un subdesarrollo socioeconómico y unas estructuras político-religiosas más propias del medioevo que de una sociedad moder$\mathrm{na}^{6}-$ la mujer se sintiese mucho más alejada de Eva en el tiempo que en su circunstancia. Así, los muy escasos derechos de la mujer soltera -entre los que no figuraba el derecho a votar, ser elegida para cargos públicos, ser funcionaria o pertenecer a una cámara de comercio- quedaban aún más cercenados al casarse. Ésta no podía hacer negocios, comprar o vender sus propiedades, administrar sus bienes, recibir herencias, ni viajar sin el per-

${ }^{5}$ Génesis; 3, 16.

${ }^{6}$ Como explican Javier Paniagua (1989) y Julián Casanova y Carlos Gil Andrés (2012), el primer tercio de siglo XX fue testigo de grandes cambios y profundas transformaciones en las bases económicas y sociales de muchos países europeos; pero, al sur de los Pirineos, el progreso avanzaba más lentamente. España era entonces un país eminentemente agrícola, pobre y atrasado, que seguía muy a la zaga el desarrollo económico, político y social alcanzado por otros países europeos, como Francia, Inglaterra o Alemania, impulsados por la marcha del capitalismo industrial. En torno a 1914, el reparto de la riqueza nacional evidenciaba una galopante injusticia social. En el ámbito rural, la miseria y las hambrunas causadas por una política librecambista que volatilizaba los precios de los principales productos de consumo (cereales y hortalizas, sobre todo), junto a un primitivismo en las técnicas de cultivo y una mentalidad patronal más propia de la Edad Media, causaban frecuentes revueltas de jornaleros, que eran aplastadas sin contemplaciones por la Guardia Civil, cuerpo creado específicamente para estos menesteres en 1844 . Y a su vez, en las ciudades, a donde acudía en busca de trabajo el sobrante de mano de obra agrícola, se hacinaba una creciente masa humana que, totalmente desprotegida frente a las durísimas condiciones laborales y los abusos de los patronos, sobrevivía muy a duras penas, alumbrada por una nueva conciencia de clase. 
miso de su marido, al que quedaba legal y materialmente sometida por su condición de casada (Arias, 1973; Astelarra, 1986; Laffitte, 1964; Sau, 1986; VV.AA., 1999).

En este sentido, el papel de la Iglesia Católica española, como guardiana de la tradición y supervisora de la moralidad -prerrogativas a las que no ha renunciado nunca-, ha sido el de actuar como un portentoso muro de contención ante el progreso social de la mujer. Había que mantener a la mujer "en su sitio" y una destacada pedagoga cristiana como Sofía Tartilán, ya lo había advertido muy claramente en sus Páginas para la educación popular: "Nuestra verdadera emancipación está dentro del hogar, en el seno de la familia” (Tartilán, 1877: 25). Esa era la misión de las famosas Escuelas del Ave María, del Padre Manjón, junto a similares iniciativas pedagógicas de los Círculos Católicos, el Patronato de la Juventud Obrera, y un amplio sector del clero que tenía a su cargo la educación infantil (Paniagua, 1989). Para ello se publicaron una gran cantidad de libros especializados en la formación moral del "bello sexo" o "sexo débil", como Flora, o la educación de una niña, un librito muy popular de 1920, escrito "para que [la niña] tomando a FLORA desde la más tierna infancia, no se separe ya de ella hasta dejarla casada y en perfecta disposición de ser tan buena esposa y madre como ha sido excelente hija" (Pascual de San Juan, 1920: 4)7.

El matrimonio resultaba, así, su ámbito natural y, en el apartado sobre "Deberes familiares", la autora de Flora dejaba muy claro cuál era el papel de cada uno de los cónyuges: "El deber del padre es procurar el sustento de su familia, protegerla y darle buen ejemplo; el de la madre, distribuir los recursos de la misma, cuidar el orden, aseo y economía, reprender, aconsejar y ser el ángel custodio del marido y de los hijos" (Pascual de San Juan, 1920: 158). Pero notemos que Flora no habla de marido y mujer, sino de

${ }^{7} \mathrm{Y}$ desde esta misma óptica se veía también la educación de las clases humildes como semilla de posibles revoluciones (ateneos obreros, escuelas sindicales, etc.), con lo cual, ser mujer y pertenecer a las clases bajas suponía un doble impedimento a la hora de acceder a una educación formal. Sólo a partir de 1931, con el advenimiento de la II República, comenzó a darse cierta paridad entre mujeres y hombres que accedían a una escolarización elemental. No obstante, el porcentaje de mujeres que accedían a titulaciones superiores era ridículo, prohibiéndosele que pudiesen cursar estudios de notario, registradores de la propiedad o jueces - cargos todos ellos que constituyeron durante muchos años feudos del poder político, social y económico de la España caciquil y reaccionaria. 
padre y madre, lo que define al matrimonio como unidad de procreación: desde el mandamiento divino, "Creced y multiplicaos" (Sagrada Biblia, Génesis, 1:28), hasta su institución sacramental por la Santa Madre Iglesia, "para casar y dar gracia a los casados, con la cual vivan entre sí pacíficamente y críen hijos para el cielo" (Astete, 1997: 48). Parir era un deber ineludible para la mujer, como nos lo recordaría el famoso padre Remigio Vilariño al lanzar el anatema contra la planificación matrimonial:

Es abominable la práctica de algunos casados inmorales y casadas malas cristianas que usan el matrimonio de tal modo que o no tengan hijos o solamente algunos. Crimen detestable, vicio abominable que trastorna la familia, mutila el alma, destroza la sociedad, engendra enfermedades, atrae maldiciones de Dios. Vicio horrendo, maldito de Dios, de la naturaleza y de la Patria. Todo matrimonio que se aparta de las reglas católicas es perverso (Vilariño, 1963).

Para estos preceptores de la moralidad cristiana, la sexualidad debía entenderse única y exclusivamente como un trámite reproductivo, carente de placer o afectividad.

Como advierte el filósofo y pedagogo cristiano Hans Wirtz, en Del eros al matrimonio (1954), lo erótico -es decir, el placer sexual- nada tenía que ver con el matrimonio ${ }^{8}$. Para la mujer cristiana, modelada en las virtudes de la Virgen María, amar debía ser sacrificio y padecimiento: "El amor es una prontitud perenne para sacrificarse por el otro. Siempre que en la unión voluntaria de dos seres humanos -en la unión del hombre y de la mujer- se crea en tal amor y padezca tal amor, podrá haber matrimonio, un matrimonio feliz, santo, eterno" (Wirtz, 1954: 12). Y de igual manera, para este exaltado exegeta, la felicidad matrimonial era un hongo veneno-

${ }^{8}$ La traducción del alemán Vom eros sur ehe es de Antonio Sancho, canónigo magistral de Mallorca, para la "Colección Hogar" de la editorial católica Studium, responsable de otros manuales como, El evangelio de la madre, Moral íntima de los cónyuges, Familia y colegio, ¿A dónde van las costumbres?, Mujer: Diario de una madre, y El arte de las artes: Educar a un niño -títulos y obras dirigidas a la formación católica de la mujer y su identidad como esposa y madre. El uso de la cursiva por parte del autor para resaltar la importancia de ciertas palabras - por ejemplo, sacrificarse y padezca- es constante a lo largo de la obra, lo que refleja una clara intención pedagógica. 
so, el resultado del egoísmo y del instinto animal que la voluntad de sacrificio y abnegación de la casta esposa-madre debía superar:

Todos los enamorados están firmemente convencidos de que el fundamento más seguro para un buen matrimonio es el amor. Amor, y el matrimonio será perfecto. Matrimonio sin amor -dicen- no es matrimonio. El "amor, como el mito más profundo de la Naturaleza" (Kierkegaard), es también el mito más profundo del matrimonio. Partiendo de él, ha de fundarse, formarse y mantenerse el matrimonio. Entonces todo irá a la perfección. Y el matrimonio será realmente... matrimonio. Todo esto parece muy justo y razonable. No se le puede objetar nada. Lo único que se puede hacer es dejar hablar a la experiencia. Y lo que ésta dice es tan sorprendente como alarmante: los matrimonios contraídos por puro amor acaban con harta frecuencia en la desdicha... (Wirtz, 1954: 11).

De ahí que nuestro experimentado preceptor llegue a la conclusión, tan lógica como inevitable, de que todo matrimonio que piense en "ser feliz" o en "estar juntos" comete un grave error:

La mayoría de los que contraen matrimonio lo hacen para... ser felices. Es un error fundamental. De este hongo venenoso brotan todas las desdichas. Al principio, el matrimonio no es más que un tímido y feliz "estar juntos”, y está lleno de tensa expectación y de consumación agradecida. No es dichoso ni desdichado. Lo será solamente al correr de los años. En muchos casos lo es ya al cabo de unas semanas... [...] Porque el matrimonio es el vía crucis voluntario, valiente y recorrido por amor, para hacer feliz al otro (Wirtz, 1954: 48-49).

En definitiva, la mujer debe "hacer feliz en vez de serlo"; debe desaparecer en el otro, vaciarse de sí misma, anularse por completo hasta llegar a existir sólo por y para su marido, siempre dispuesta a sacrificarse y sufrir intensamente por amor:

El matrimonio es -de cualquier lado que se le mire- sacrificio, nada más que sacrificio. Cuando falta la voluntad para el sacrificio, falta también la voluntad para el matrimonio. [...] ¿Amor? Lo que en este sentido se llama amor..., es consonancia de sentimientos, que a veces dura hasta el umbral del matrimonio, a veces hasta el final del primer año, hasta el primer hijo...; mas, por lo regular, se pierde ya antes, sin producir melodía, en medio de la árida monotonía de todos los días y en medio 
del estrépito del mundo exterior. Porque el amor sin sacrificio es como el cuerpo sin alma y como el sol sin calor: es cosa muerta, de todo punto imposible; no es más que un tremendo engaño. [...] Sacrificio en el matrimonio significa: abnegación continua; significa que ya no se piensa más en la propia persona, sino solamente en la del otro (Wirtz, 1954: 22-23).

De esta manera, el amor conyugal se convertía en algo muy próximo a la esclavitud, con el mismo sentido de sacrificio y renuncia voluntaria con el que algunas órdenes monacales -como es el caso de las "Esclavas de Jesús”- entienden su papel como mujeres dentro de la Iglesia, al identificarse con el sufrimiento del Hijo de Dios: "el siervo que obedece y sirve por amor” (Nacar Fuster y Colunga, 1986). Las cosas no podían ser de otra manera.

Por supuesto, la mujer siempre ha tenido a la historia en su contra (Bramón, 2009 y 2010; Gómez-Acebo, 1999; Moreno, 2007 y 2010; Navarro, 1987; Witherup, 2003). Sin embargo, con el relevo generacional que acompaña al naciente siglo XX, llegan aires de fuera, ansias de libertad y progreso que cifraban en los logros de países como los Estados Unidos, Inglaterra, Francia, Alemania, Holanda y Bélgica un esbozo de utopía realizable (Wollstonecraft, 1994) ${ }^{9}$. Como sugiere el historiador Javier Paniagua, eran tiempos de grandes cambios y grandes retos,

... de lucha contra la desigualdad, contra los privilegios de clase o corporativos, de la búsqueda de una cultura de masas, con el deseo de abarcar en un mismo proyecto a toda la humanidad, de comprender otras culturas; de eliminar la barrera entre los sexos, con la igualdad de hombres y mujeres; de proteger la infancia y a los viejos; de luchar contra el dolor y la tortura. [...] Regímenes y gobiernos cayeron y nuevas políticas transformaron las realidades sociales. Viejas costumbres familiares se alteraron y el deseo de extender la felicidad en este mundo fue un propósito político y social declarado (Paniagua, 1989: 6).

${ }^{9}$ Estos países habían sido la máquina del tren del progreso occidental. La medicina, la biología, la ingeniería, las comunicaciones y el arte habían encontrado en estas sociedades de principios de siglo un suelo fértil y propicio. Y junto al progreso científico aparece no sólo la capacidad de los hombres y mujeres para acceder a los beneficios sociales, sino a entender dichos beneficios como derechos inherentes a la condición de ciudadano, tal como se reclamaba desde las filas progresistas. 
Se reclamaban unas nuevas coordenadas vitales, éticas y estéticas, y cada vez era mayor el número de españoles que veían en ese amanecer del siglo XX una puerta abierta al cambio y a un mundo mejor. Pero eran una minoría. En 1909, con la nostalgia propia del machismo de la época, Gómez Baquero (en Nuevo Mundo, 29-IV-1909) lamentaba que ya no hubiese mujeres como las de antes:

La señora española de la clase media: ese noble y bello tipo moral que hemos conocido en la infancia: la mujer hacendosa, consagrada al hogar, esclava, con la dulce esclavitud del cariño, de su marido y de sus hijos y al mismo tiempo muy señora, muy poseída de su dignidad de esposa... Ese tipo femenino va desapareciendo... Lo extinguen el lujo, la libertad, el contagio de los ejemplos perniciosos que empiezan en los colegios y siguen en las amistades, también la literatura inmoral y frívola... La mujer va desertando del hogar, llena los lugares de diversiones, sale a menudo en la crónica de sucesos que es una especie de galería del crimen y toma parte en las manifestaciones políticas... Cada día se hace más difícil distinguir a las señoras de las que no lo son. Entre la mujer española de hace treinta años y la de hoy hay una diferencia que parece de un siglo ${ }^{10}$.

El temor al cambio era patente y, una vez más en la historia del conservadurismo reaccionario, la "culpa" la tenía esa influencia extranjera americana, por supuesto- que Antonio y Manuel Machado identifican, con mucha ironía, como fuerza disolvente de los valores y costumbres tradicionales, un atentado contra la esencia intrahistórica de lo hispánico:

... En Europa/... en la misma España/ que era su parte más recia, / todo se americaniza, / se desustancia, y de fuera/ viene todo: canto, música, / juegos, bailes y peleas, / que lo castizo se acaba/ y día vendrá en que venga/ hasta el agua del bautismo/ de Yanquilandia en botellas. / Todo se democratiza: / Barato y a la carrera/ Se hace todo, porque nada/ Vale un pepino: las perlas/ Que hizo usted tan despacito, / Ya se fabrican por gruesas. / Ya todo es uno y lo mismo. / El sexo es una entelequia. / Los hombres y las mujeres/ Como ellos dicen, se encueran/ Por menos de nada y... nada/ Ni notan sus diferencias (Díaz Plaja, 1975: 492).

${ }^{10}$ Artículo de Gómez Baquero, en Nuevo Mundo, 29-IV-1909, recogido por Fernando Díaz Plaja (1975). 
Y dicen bien los hermanos Machado cuando notan que "todo se democratiza", pues es precisamente el impulso político de la igualdad entre el hombre y la mujer lo que escandaliza y lo que subyace en la denuncia "moral" de los tradicionalistas. La mujer resultaba frívola porque pretendía liberarse de esa felicidad hogareña que la mantenía enjaulada, aunque en algunos casos fuese una jaula de oro. Era insensata porque pretendía abrirse paso en el mundo, frente al hombre o incluso compitiendo con él ${ }^{11}$.

Como cabía suponer, la respuesta del teatro no se hizo esperar y situó a la mujer en la encrucijada escénica del cambio milenario (Berenguer, 1988; Huerta, 2003; Ruiz, 2011). El papel de abanderado en esta lid correspondería a Manuel Linares Rivas, que como ya ha señalado Ángel Berenguer, se sitúa dentro de unas coordenadas éticas y estéticas en línea con una tendencia novadora y rupturista

\begin{abstract}
que niega, denuncia y rompe la alianza establecida entre la nobleza y la gran burguesía y, al mismo tiempo, afirma la posible identificación de los intereses de clase de la pequeña burguesía con el proletariado. Cree en la necesidad de cambios radicales y/o revolucionarios, y se expresa en el carácter radical progresista del discurso político que emplea en su teatro (teatro social), o en la apuesta constante por una radical transformación de los medios teatrales que emplea, aceptando las nuevas formas que se producen en otras áreas de la producción artística (expresionismo, surrealismo) (Berenguer, 1988: 24).
\end{abstract}

${ }^{11}$ El pensamiento ilustrado del siglo XVIII (Espigado, 2003; Morant, 2003), reflejado en las obras de Feijoo en Teatro crítico y Moratín en El sí de las niñas, había defendido el principio de igualdad moral (inteligencias y aptitudes) entre el hombre y la mujer. Y a su vez, el liberalismo realista/naturalista burgués del siglo XIX (Charnon-Deutsch,1990; Cook, 1976; Duarte, 1987; Jaffe, 1995) reflejado en la obra de escritores como Galdós, en Tristana o Fortunata y Jacinta (Acosta,1988; Aldaraca, 1992; Bodóns, 1993; Buck, 1994; Charnon-Deutsch, 1994) o Clarín en La Regenta (Alegre, 1986; Ciplijauskaite, 1984; Ibarra, 1972; Ibarra, 1974; Ortiz, 1971) dieron un giro de tuerca a la consideración social de la mujer (como hija/esposa/madre), introduciendo la problemática de la sexualidad en el matrimonio (la mujer como amante). Pero no será hasta las primeras décadas del siglo XX (es el caso temprano de Linares Rivas en las obras aducidas) que la mujer asuma en la literatura el rango de ciudadana y sirva como prisma de una problemática social revolucionaria que comienza con el sufragismo a principios de siglo y conduce a los diversos movimientos feministas de últimas décadas del siglo XX y principios del XXI (Hansen y Philipson, 1990; Hormigón, 1996). 
En el teatro linariano late una poderosa denuncia de la situación de la mujer: su educación para ser víctima, su marginación en el mundo laboral e intelectual y el paternalismo condescendiente de una sociedad machista que sólo veía en ella a un ser frágil, carente de voluntad propia e incapaz de hacer frente a la vida por sí sola.

Así, con el sugerente título de Aire de fuera, una obra estrenada en 1903, Linares Rivas saca a la palestra escénica la bestia negra del machismo cristiano: el adulterio. Su novedad no radica en el tema, que es de rancio abolengo teatral, sino en su tratamiento, pues la mujer adúltera, Carlota, no se siente culpable y su marido, Baltasar, no la condena porque, entre otras cosas, reconoce en el adulterio de su esposa la legitimidad de una necesidad sexual que él ha desatendido: “...y por mi culpa caíste en tu culpa. Lo reconozco; es muy tardío; pero lo reconozco con la pesadumbre inmensa de lo inevitable... y tu culpa es mi culpa" (66-67). Pero, en realidad, la única culpable es la sociedad machista en la que viven, y la solución que propone Baltasar resultaría, en aquellos momentos, tan escasamente calderoniana y tan poco habitual sobre el escenario como en la vida misma: una separación amistosa. Desde luego, no era esa la solución que el ínclito Echegaray hubiera dado al problema (Huerta, 2003) ${ }^{12}$.

El reconocimiento de la sexualidad en la mujer y la propuesta del divorcio escandalizaron sobremanera al público burgués de su época. A diferencia de la mujer soltera, a la que la Iglesia reconoce su capacidad sexual sólo y exclusivamente en función del placer físico o carnal -de ahí, naturalmente, que la fornicación sea pecado-, a la mujer casada se le niega esa misma capacidad, como si su sexualidad constituyese una suerte de castración o ablación derivada del matrimonio. Pero, ċacaso no tiene la mujer derecho a la satisfacción sexual? ¿No debería ésta considerarse conditio sine qua non de la felicidad matrimonial? El diálogo entre Magdalena y Carlota, los dos personajes femeninos principales, es harto más que sugerente a este respecto. Magdalena es una mujer profundamente infeliz en su matrimonio, maltratada por su marido y obligada por ley a volver con su maltratador; harta de sufrir, decide huir:

${ }^{12}$ Me refiero al recurso melodramático de la pasión (violencia, sangre, etc.) como final/solución de un conflicto: la venganza, el adulterio, el honor ultrajado o el suicidio por amor. 


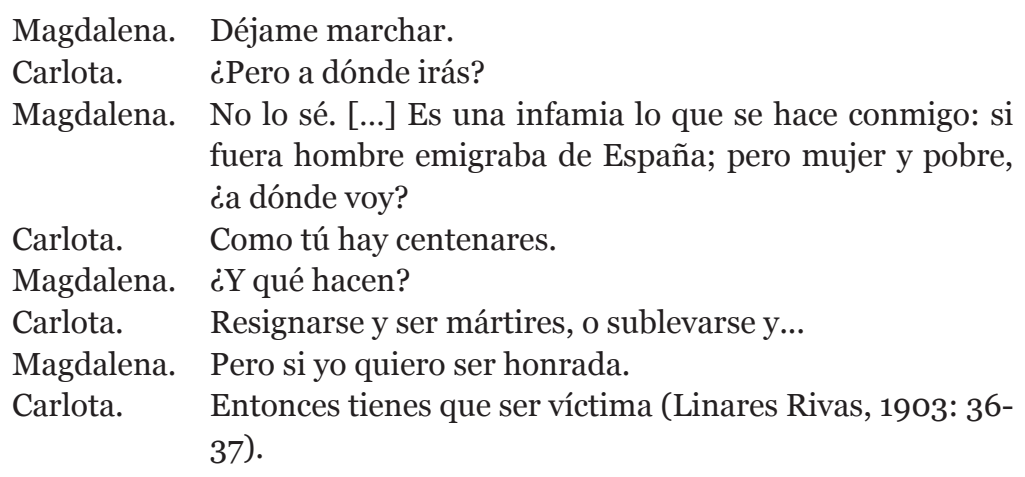

Como sugiere Baltasar -y no es poca ironía que sea precisamente él quien lo sugiera- el problema de Magdalena es que vive en un "hogar sin fuego", sin "afectos y palabras de consuelo", en un matrimonio "frío". Y esta consideración matiza aún más la sugerencia de Carlota de sublevarse y..., que es el ser o no ser de la mujer nueva: permanecer en esa cárcel psicológica que es la honrada resignación cristiana de la buena hija-esposa-madre, o sublevarse y... abrir las puertas a ese aire de fuera que anuncia la existencia de otros mundos posibles, mundos de igualdad y justicia. Por eso no es una sorpresa ni una incoherencia que quien proponga esa postura rebelde sea precisamente Carlota, la mujer adúltera.

¿Es la alternativa que aconseja Carlota a las mujeres una rebelión sexual próxima a lo que algunos años más tarde daría en llamarse amor libre? Desde luego, no es una consideración del todo infundada. Como hemos dicho, ni las palabras ni el comportamiento de Carlota respaldan esa imagen de mujer frívola y concupiscente que se proponía desde las filas de la crítica católica y tradicionalista para explicar el adulterio en esta obra. Por el contrario, teniendo en cuenta el comportamiento conyugal de su marido a lo Flora, el adulterio de la joven esposa resulta mucho más convincente como una reacción premeditada y consciente, como una forma de rebeldía ante el tedio de una relación matrimonial en la que no le falta de nada excepto, quizá, la satisfacción sexual.

Ya en La ciencia de los hombres, de 1893, y en similares circunstancias a las de Aire de fuera, un Eduardo menos progresista que Baltasar recrimina a su esposa Rosalía por declararse "insatisfecha” en su matrimonio, a pesar de tenerlo todo: 
Ven acá, más junto a mí,/ y ahora contéstame, di,/ ¿habrá una mujer que obtenga/ más libertad, más franquicia,/ de manos de su marido/ que la que siempre has tenido?.../ Porque en eso, Rosalía,/ nada te quise negar,/ ipues a una mujer honrada/ el que no la prohiban nada,/ ya es darle mucho a guardar.../ Tú eres señora en tu casa,/ teatros, fiestas y reuniones,/ sin que en nada tengas tasa;/ pero tú no me agradeces/ el sacrificio (13-14).

A lo que Rosalía le responde recordándole que, en el matrimonio, el marido debe a su mujer algo más que su sacrificio o esfuerzo como proveedor, algo más que un palco de teatro, un coche, viajes, joyas y lujo: "No: es que me casé contigo/ para que fueras conmigo,/ no para estar siempre sola./ No vamos nunca los dos/ juntos, y si es aburrido,/ me aburro con mi marido/ que es como lo manda Dios" (14). Ella está dispuesta a renunciar a todo el lujo y confort material a cambio de una mayor atención amorosa por parte de su esposo: "Dejaré el coche, el abono,/ viviremos bajo un tono/ modesto”. Pero él responde: “iNi pensarlo! Yo he nacido/ para el trabajo, iPues duro,/ y a trabajar!” (15).

Educado en el concepto tradicional del matrimonio cristiano, en el que la sexualidad, cuando no está al servicio de la procreación, es aborrecible, ese marido "sacrificado" que es Eduardo no entiende el requerimiento de Rosalía, ni la velada alusión a los peligros de una mujer que está "siempre sola":

Eduardo. iHoras que robé a tu amor, sangre que robé a mis venas, para que volvieran llenas/ de luz a darte esplendor!... Ya ves que no me es posible: Vuelve a tu antigua alegría.

Rosalía. ¿Pero sola?

Eduardo. iRosalía!

Rosalía. iEduardo!

Eduardo. iSi es imposible!

[...] Mientras viene don José, que vendrá a almorzar aquí, voy a ver si tomo ahí unas notas. 
Rosalía. Bien, me iré:

¿Pero sola?

Eduardo. Ten paciencia, que te prometo ir contigo.

Rosalía. ¿Hoy vas a salir conmigo?

Eduardo. No. Hoy tengo que ir a la Audiencia (15-16).

Esa incapacidad de Eduardo para comprender el tedio insoportable que genera la "soledad sexual" de su mujer será motivo inevitable de un adulterio que, de igual manera que no logra entender en sus causas, no reconoce en sus consecuencias.

Para Linares, la mujer -llámese Carlota, Magdalena o Rosalía- es el símbolo por excelencia del sufrimiento, la desigualdad y la injusticia social, y la única solución a ese mal es la educación. De ahí que Baltasar ponga todas sus esperanzas en su hija Carlota -y no es coincidencia que se llame igual que su madre- a quien propone educar fuera de España, lejos de las garras de la Iglesia:

Baltasar. En cuanto nuestra Carlota tenga edad para ello, estoy completamente decidido a enviarla fuera.

Gerardo. Es una idea muy sensata.

Eduardo. En ti es natural esa preocupación. Te educaste en Bélgica, después dos años en los estados Unidos, y has vuelto renegando de ser español.

Baltasar. Renegando no; muy honrado de serlo, pero muy entristecido viendo que en mi patria se apedrean los trenes; que en las ciudades donde se bañan doscientas personas se quedan sin agua para beber los treinta y ocho o cuarenta mil restantes; viendo los campos cultivados como en tiempo del rey Wamba.

Eduardo. Llévala, llévala.

Baltasar. Ya lo creo; y que viaje y que vea, para que si el día de mañana tiene desgracia en su vida, sepa que el mundo no se hunde porque falte un padre o porque le abandone un marido (7-8).

Naturalmente, la educación puede ser una solución a largo plazo para la mujer burguesa; pero Linares es consciente de que, para la inmensa mayoría de mujeres españolas, el cambio no se dará por esos medios. De ahí que, 
a partir del triunfo de la revolución de los Soviets en 1917, el autor radicalice su posicionamiento y encomiende el protagonismo de la revolución social a las clases trabajadoras, a las que considera más dispuestas, por sufrir una situación más desesperada y porque están menos contagiadas por la hipócrita moralidad burguesa.

Para el proletariado, la moral y el honor son un lujo incompatible con el hambre y la necesidad. Como sugiere Tabardillo, un personaje de La espuma del champagne, estrenada en 1914:

Lo más hermoso para vosotras es tener una renta; también es hermoso y digno el buscársela trabajando, pero el trabajo de las mujeres en España no es más que una explotación pagada con una limosna. Nadie, o muy pocos, se cuidan de buscaros medios honestos y bien retribuidos, y en cambio muchos se cuidan de moralizaros gratuitamente. No os dicen: "honradas... y a ganar mucho", no; os dicen: "honradas... y a moriros de hambre" (10).

Como sugiere Pepe a su hermana Sebastiana, en esta misma obra, esa explotación es un eximente de la conciencia, para los pobres:

Pepe. Hermana, la vida es miserable y ruin...; sí, ruin y miserable..., pero hay que vivirla.

Sebas. ¿Cómo? Dime cómo.

Pepe. Lo que yo puedo decirte ya está dicho. Adiós.

Sebas. ¿Qué va a ser de mí...?

Pepe. No lo sé. Quizás con esta carga menos puedas salir a flote... Si te hundes antes de que mi estrella me permita venir a socorreros, no seré yo quien te recrimine.... iVive, hermana, vive!

Sebas. ¿Pero cómo?

Pepe. Eso es lo más miserable. Como puedas, Sebastiana, como puedas..., ipero vive!

Sebas. Si no fuese por la conciencia...

Pepe. Os dejo a madre y a ti porque la miseria me obliga a marchar; pero oye, hermana, oye: aquí dejo también mi conciencia.

Sebas. iEso no, Pepe!

Pepe. Soy pobre; no puedo permitirme lujos en el equipaje (8).

En el contexto argumental de la pieza, el consejo de Pepe a Sebastiana, “... como puedas... ipero vive!”, alude claramente a la prostitución. Pero no nos equivoquemos. Linares no sugiere ese camino como respuesta ante la 
pobreza y desigualdad social. Lo que en realidad propone es algo mucho más radical: la superación de esas trabas morales que, incluso en las circunstancias más desesperadas, neutralizan la capacidad de acción y libertad de la mujer, negándole no sólo el control sobre su voluntad, sino también sobre su propio cuerpo: “iEso no, Pepe!”. En este sentido, es altamente significativo el diálogo entre Sebastiana y la Rabanitos - una mujer trabajadora que pierde su trabajo y tiene que prostituirse para dar de comer a su familia-, cuando ésta llega a casa de la primera y observa la enfermedad, el hambre y la miseria que la rodea:

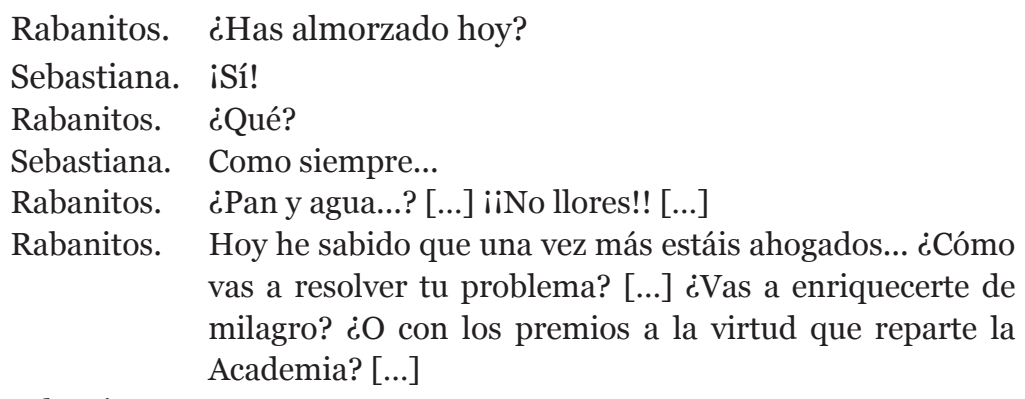

Sebastiana. iJesusa!

Rabanitos. No te espantes, ni vuelvas a llamarme Jesusa: ése era el nombre de los días negros. Ahora me llamo Rabanitos, ila Rabanitos! De pequeña decía por las calles: irabanitos como el agua tiernos!, ¿̇quién los quiere?; y nadie los quería. Ahora digo: iRabanitos, la Rabanitos!... ċquién la quiere? ¿Y la quieren, Sebastiana, la quieren; quieren a la Rabanitos como agua de mayo o sol de invierno.

Sebastiana. Haces mal en...

Rabanitos. ¿Mal? ¿Mal en no morirme de hambre y en no dejar que se mueran los míos?... ¿ ¿Mal en que mis viejos tengan casa y comida?... ¿Dejarlos sufrir, pudiendo socorrerlos sin hacer daño a nadie?... iNo! Eso no lo hacen más que los buenos... (8-10).

Cuando Sebastiana se queja de que "en casa no hay ni para la medicina de mi madre...", la Rabanitos añade. "Mejor, mejor y mejor. Cuando ya no hay manera de empeorar en nada, todo lo que viene es mejoría" (11). Como diría muchos años más tarde Janis Joplin, en su balada "Me and Bobby McGee”, en un desgarrado grito de rebeldía ante la sociedad burguesa de 
su tiempo: "Freedom is just another word for nothing left to lose"13. Si la religión es el opio de los pueblos, la moralidad y la honradez son las cadenas que mantienen a la "mujer nueva" del naciente siglo XX atada y sumisa ante la explotación burguesa ${ }^{14}$.

A este respecto, como sugiere Baltasar, no se debe confundir la caridad cristiana con la justicia social, ni es ética la resignación ante la injusticia. La mujer, como el hombre, tiene el derecho a ser feliz en este mundo: "Hay algo más que piedad: el hombre, el ser humano, tiene derecho a vivir feliz y obligación de luchar para serlo. Rendirse, nunca; caer, cuando sean más fuertes; pero, aún caídos, esforzarse en volver a la vida. Contra el poder bastardo, contra la ley, contra todos..." (40).

A partir de este momento y hasta su última obra conocida, como alfa y omega de un mismo planteamiento ideológico, Linares Rivas escribirá siempre en defensa del espíritu vitalista y revolucionario de la mujer. Desde ese compromiso, responderá desde el escenario a consideraciones y circunstancias reales y propias del momento. Así, treinta años más tarde, en el manuscrito inédito de Fausto y Margarita ${ }^{15}$, fechado en un ominoso septiembre de 1935 en una España todavía republicana, podemos oír a la protagonista, Margarita, hacerse eco de la intención política que encierran las palabras de Baltasar cuando dice a un Fausto que, al fin, se ha decidido a rebelarse y rescatar su libertad, su "alma”, de las garras del opresor:

${ }^{13}$ Véase la página oficial de la cantante: www.janisjoplin.com/music.php. Janis Joplin fue un símbolo de la contracultura estadounidense de los años sesenta y destacó en el movimiento de liberación sexual de la mujer y contra la guerra de Vietnam. Murió en 1970, a los 27 años y su balada, "Me and Bobby McGee", fue la canción más cantada en 1971. Traducida al castellano, la frase citada diría: "La libertad significa no tener nada que perder".

${ }^{14}$ En 1844, Karl Marx afirmaba: "La religión es el opio de los pueblos" --traducción del alemán "Die Religion ... Sie ist das Opium des Volkes" (1968 [1843]). Y una destacada revolucionaria soviética, Alejandra Kolontay (2000), equipara la libertad sexual (superación de la moral reaccionaria, particularmente en torno al divorcio y el aborto) con la libertad social (superación de las trabas socioeconómicas que circunscriben a la mujer al ámbito del hogar, particularmente relacionadas con la inserción laboral).

${ }^{15}$ Linares Rivas, Manuel (1999 [1936]). Hace unos años, descubrí en La Coruña diversos documentos, notas y obras inéditas o desconocidas de Linares, entre ellas estaba el manuscrito de Fausto y Margarita, firmado y fechado por el autor en el Pazo de La Peregrina, en septiembre de 1935. Actualmente, éste y otros manuscritos se encuentran en la Biblioteca de la Diputación Provincial de La Coruña. La pieza fue estrenada en Madrid por José Linares, hijo del autor, en 1943. 
Margarita. Tú eras un poco como la España de antes: lo tenías todo para vencer, todo, y porque una voz chillona te decía que no tenías nada, tú te dejabas convencer mansamente y que en la impunidad te escarnecieran, te martirizaran, y hasta que fuera ya un gran favor el que únicamente te mataran.

Fausto. Cierto. Sólo resignación tenía.

Margarita. Y yo quiero que seas como la España de hoy: ife, mucha fe!: iánimo, mucho ánimo...! y lo demás ya irá viniendo por sí solo $^{16}$.

Este planteamiento del papel de la mujer como fulcro de la conciencia revolucionaria de la pequeña burguesía y el proletariado le ganaría al autor la etiqueta de feminista, impuesta desde las filas del conservadurismo católico-burgués con afán de descalificar y desprestigiar su obra. Pero Linares se sentía orgulloso de esa etiqueta, como afirma en Vilanos (s/f.):

Muchas veces me tienen dicho que soy un defensor exagerado de las mujeres. [Y] es gran verdad mi profundísimo entusiasmo por ellas, considerándolas en todos los aspectos muy superiores a nosotros. Yo no lo veré, porque el feminismo va muy despacio, pero creo firmemente que las mujeres han de gobernar mejor que los hombres, por lo menos hasta que se maleen y piensen como hombres. Hoy por hoy, tienen más sensibilidad, más rectitud y más firmeza que el llamado, con algo de ironía, sexo fuerte. iLas fuertes son ellas! (Linares Rivas, s/f: 11).

En 1935, un año antes de morir, Linares Rivas estaba convencido de que la hora de la mujer había llegado y, más que profetizar con el halago, creía exponer un hecho histórico. Y tenía razón, aunque luego se la quitaran en 1939.

\section{Referencias}

Acosta de Hess, J. (1988). Galdós y la novela de adulterio. Madrid: Pliegos. Aldaraca, Bridget A. (1992). El ángel del hogar: Galdós y la ideología de la domesticidad en España. Madrid: Visor.

${ }^{16}$ Cito de la edición facsimilar de Fausto y Margarita, recogido por Fidel López Criado (1999). 
Alegre, C. (1986). Ana Ozores y Fermín de Pas: biografías paralelas en La Regenta de Clarín.Scr@tura, 1, 5-13.

Arias, M. (1973). La liberación de la mujer. Barcelona: Salvat.

Astelarra, J. (1986). Las mujeres podemos: Otra visión política. Madrid: Icaria.

Astete, G. (1977). Catecismo de la Doctrina Cristiana. Salamanca: Calatrava.

Berenguer Castellary, Á. (1988). El teatro en el siglo XX (hasta 1939). Madrid: Taurus.

Bodóns, T. (1993). Releyendo Tristana, en Nueva Revista de Fỉlología Hispánica, 41(2), 471-487.

Bramón, D. (2009). Ser mujer y musulmana. Barcelona: Bellaterra. (2010). En torno al Islam y las musulmanas. Barcelona: Bellaterra.

Buck, D. C. (1994). Geographical Places, Architectural Spaces, and Gender in Doña Perfecta. Romance Languages Annual, 6, 417- 421.

Caine, B. y Sluga, G. (2000). Género e historia: mujeres en el cambio sociocultural europeo, de 1780 a 1920 . Madrid: Narcea.

Casanova, J. y Gil Andrés, C. (2012). Breve historia de España en el siglo XX. Madrid: Planeta.

Charnon-Deutsch, L. (1990). Gender and representations: Women in Spanish realist fiction. Amsterdam: John Benjamins.

(1994). Narratives of desire: Nineteenth-Century Spanish fiction by women. University Park: Pennsylvania State University Press.

Ciplijauskaite, B. (1984). La mujer insatisfecha: el adulterio en la novela realista. Barcelona: Edhasa.

Cook, T. (1976). El feminismo en la novela de la Condesa de Pardo Bazán. La Coruña: Diputación Provincial.

Díaz Plaja, G. (1975). La sociedad española en fotografías y documentos. Barcelona: Plaza y Janés.

Duarte Berrocal, M. I. (1987). Juan Valera y la visión de la mujer finisecular. En VV.AA., Realidad histórica e invención en torno a la mujer (pp. 133-153). Málaga: Diputación Provincial.

Espigado Tocino, M. G. (2003). La Junta de Cádiz: entre la ruptura y la reproducción social. En Espigado Tocino, G. y de la Pascua, Ma J. (eds.), Frasquita Larrea y Aherán: Europeas y españolas en la Ilustración y el Romanticismo (pp. 243-266). Cadiz: Universidad de Cádiz.

Gancho, C. (2003). Adán, ¿dónde estás?: Tras los hombres y las mujeres de la Biblia. Madrid: Editorial Caparrós.

Gómez-Acebo, I. (1999). María, mujer mediterránea. Bilbao: DB.

Hansen, K. T.; Philipson, I. J. (eds.) (1990). Women, class, and the feminist imagination: A socialist-feminist reader. Philadelphia: Temple University. Hormigón, J. A. (1996). Autoras en la historia del teatro español (1500-1994). Madrid: Publicaciones de la Asociación de Directores de Escena de España. 
Huerta Calvo, J. (2003). Historia del teatro español. Del siglo XVIII a la actualidad. Madrid: Gredos.

Ibarra, F. (1972). Clarín y Azorín: El matrimonio y el papel de la mujer española. Discrepancia y acuerdo. Hispania, 55(2), 45-54. (1974). Clarín y la liberación de la mujer. Hispanófila, 51(3), 27-33.

Jaffe, C. M. (1995). Genre and the construction of gender in La desheredada: Desire and the masculine narrative gaze. En López de Martínez, A. (ed.), A Ricardo Gullón: Sus discípulos (pp. 121-130). Eire, Pennsylvania: ALDEU.

Kolontay, A. (2000). La mujer nueva y la moral sexual. México: Fondo de Cultura Económica.

Laffitte, M. (1964). La mujer en España. Madrid: Aguilar.

Linares Rivas, M. (1893). La ciencia de los hombres. Madrid: Velasco. (1903). Aire de fuera. Madrid: El Teatro Moderno. (1929). La espuma del champagne. Madrid: El Teatro Moderno. (1999 [1936]). Fausto y Margarita, facsímil, en El teatro de Manuel Linares Rivas. A Coruña: Diputación de A Coruña. (s/f). Vilanos. Manuscrito depositado en la Biblioteca de la Diputación Provincial de La Coruña.

López Criado, F. (1999). El teatro de Manuel Linares Rivas. La Coruña: Diputación de A Coruña.

MacInnes, J. (2008). La tercera revolución de la modernidad. La revolución reproductiva. Revista Española de Investigaciones Sociológicas (Reis), 122, 89-118.

Marcos, S. (2004). Religión y género. Madrid: Trotta.

Marx, K. (1968 [1843]). Crítica de la Fïlosofía del Estado de Hegel. México: Grijalbo.

Morant Deusa, I. (2003). Las mujeres en los espacios del saber ilustrado. En Espigado Tocino, G. y de la Pascua, Ma José (eds.), Frasquita Larrea y Aherán: Europeas y españolas en la Ilustración y el Romanticismo (pp. 55-79). Cádiz: Universidad de Cádiz.

Moreno Koch, Y. (2007). La mujer judía. Madrid: El Almendro. (2010). Hijas de Israel y Sefarad. Madrid: Universidad de Castilla-La Mancha.

Muraro, L. (1991). Le ordine simbolico della madre. Turín: Riuniti.

Nacar Fuster, E. y Colunga Cueto, A. (1986). Sagrada Biblia. Madrid: Biblioteca de Autores Cristianos.

Navarro, M. (1987). María, la mujer: ensayo psicológico-bíblico. Madrid: Publicaciones Claretianas.

Olmos, C. y Silva, R. (2011). El desarrollo del estado de bienestar en los países capitalistas avanzados: Un enfoque socio-histórico. Revista Sociedad \& Equidad, 1, 23-54. 
Ortiz Aponte, S. (1971). Las mujeres de Clarín: Esperpentos y camafeos. Río Piedras: Universidad de Puerto Rico.

Osborne, R. (1993). La construcción sexual de la realidad. Madrid: Cátedra.

Paniagua, J. (1989). España: Siglo XX: 1898-1931. Madrid: Anaya.

Pascual de San Juan, P. (1920). Flora, o la educación de una niña. Barcelona: Paluzíe.

Payne, S. (1984). Spanish catholicism: An historical overview. Wisconsin: UWP.

Picó López, J. (1987). Teorías sobre el Estado de Bienestar. Madrid: Siglo XXI Editores.

Ruiz Ramón, F. (2011). Historia del teatro español del siglo XX. Madrid: Cátedra.

Sau, V. (1986). Ser mujer: El fin de una imagen tradicional. Madrid: Icaria.

Tartilán, S. (1877). Páginas para la educación popular. Madrid: Imprenta de Enrique Vicente.

Vilariño, R. (1963). El mensajero del Corazón de Jesús. Bilbao: Pastoral.

VV.AA. (1999). Las mujeres entre la historia y la sociedad contemporánea. Barcelona: Consejería de Bienestar Social. Dirección General de la Mujer.

Wirtz, H. (1954). Del eros al matrimonio. Madrid: Studium.

Witherup, R. D. (2003). Biblical fundamentalism: What every catholic should know. Baltimore: Liturgical Press.

Wollstonecraft, M. (1994). Vindicación de los derechos de la mujer. Madrid: Cátedra. 